\title{
OBSERVATIONS ON THE NUTRITION AND GROWTH OF NEW-BORN INFANTS
}

AN ANALYSIS OF THREE HUNDRED CLINICAL CHARTS

WALTER REEVE RAMSEY, M.D.

Associate Professor of Pediatrics, University of Minnesota

ST. PAUL

AND

A. G. ALLEY, M.D.

Teaching Fellow in the Department of Pediatrics, University of Minnesota MINNEAPOLIS

The medical profession is very reluctant to adopt new standards, but having been once convinced as to their correctness, they are just as loath to discard them. The result is that certain standards such as weights and measures, for example, are copied by one writer after another for years without any one, or at least very few, taking the trouble to verify their correctness. Standards which are correct in one country are often quite incorrect in another country, under different conditions.

The following observations were made from the charts in the ward for new-born of the University Hospital where, owing to the efforts of Dr. Sedgwick, chief of the Pediatric Department, and the cooperation of Dr. Litzenberg, chief of the Obstetric Clinic, all new-born infants come under the pediatric service directly after birth.

The points to be ascertained from an analysis of the charts were as follows:

The average birth weight of infants, male and female.

Average daily amounts of milk received from the mother.

Average caloric intake of babies who were gaining in weight, computed as to number of calories per kilogram of body weight.

Average initial loss in weight.

Apparent cause of the initial loss in weight.

Initial loss in weight in babies who had water in addition to the nursings, compared with that in those who had no water. (In a large series of cases every other one had water.)

Whether the initial loss in large infants was relatively greater than in smaller ones.

Average time during which the initial loss continued.

*Submitted for publication April 22, 1918.

* Read before the third annual meeting of the Middle States Pediatric Society, Dec. 10, 1917. 
Average time when the babies began to regain lost weight.

What factors seemed to determine the gain in weight.

Had the number of stools anything to do with the failure to gain?

What is the average daily number of stools in normal infants during the first ten days?

Does the number of stools depend on the quantity of food received?

What is the average gain in weight during the first ten days?

Does the average infant regain its birth weight during the first ten days?

The average birth weight as given by Camerer and which has been generally accepted and copied widely, is, for boys, 3,400 gm., and for girls, 3,200 gm.

In 300 new-born infants born in the University Hospital the average weights were, boys $3,391 \mathrm{gm}$., females $3,276 \mathrm{gm}$.

The average daily intake of breast milk was as follows:

\begin{tabular}{lcccccccccc} 
& \multicolumn{1}{c}{} & 2d & $3 \mathrm{~d}$ & 4 th & 5 th & 6 th & 7 th & 8 th & 9 th & 10 th \\
Our amounts, Gm....... & 39 & 100 & 170 & 234 & 275 & 304 & 336 & 352 & 365 \\
Camerer's amounts, Gm. & 91 & 247 & 337 & 350 & 390 & 470 & $\ldots$ & $\ldots$ & 500
\end{tabular}

As will be noticed, our averages are much smaller. These amounts were determined by five nursings in twenty-four hours at four-hour intervals.

The caloric need of infants as computed by Heubner and Rubner is 100 to 110 calories per kilogram of body weight. This rule has been generally accepted, it being recognized and pointed out by Czerny, Keller and others that there are exceptions in which infants will gain for considerable periods on a less number of calories. Other observers including Cramer ${ }^{1}$ and Gaus ${ }^{2}$ in Europe, and Morse and Talbot ${ }^{3}$ in this country, believe that the rule of 100 calories per kilogram does not apply to babies during the first days, as they gain on less amounts. Salge points out that in cases in which infants: gain apparently on a less number of calories than 100 per kilogram the milk is extremely rich in fat and the caloric deficiency is only apparent.

All of our patients who made good gains and left the hospital weighing more than the birth weight, made their gain on much less than 100 calories per kilogram of body weight.

For example, Baby 11578, weight $3,760 \mathrm{gm}$., gained $360 \mathrm{gm}$. in seven days. Calories per kilogram per day $-55,52,56,67,73,80,67$; average, 64. Average gain per day, $51 \mathrm{gm}$.

1. Cramer: München. med. Wchnschr., 1903, 2, 1153.

2. Gauss: Jahrb. f. Kinderh., 1902, N. S., 55, 129. 1915.

3. Morse and Talbot: Diseases of New-Born and Infant Feeding. McMillan, 
Baby 11572 , weight $3,325 \mathrm{gm}$., gained $260 \mathrm{gm}$. in seven days, or an average of $37 \mathrm{gm}$. per day on an average daily quotient of 74 calories.

Baby 12505 , birth weight $3,780 \mathrm{gm}$., had no apparent initial loss in weight. Received $60 \mathrm{gm}$. of milk on the second day and began to gain on the third day. This baby was complemented in order to bring up the quantity of milk to approximate 100 calories per kilogram. It was found, however, in this case, as well as in several others in which this was attempted, that the babies promptly developed diarrhea, with watery, frequent stools and the amount of milk had to be much reduced. This infant only gained $16 \mathrm{gm}$. per day on an average caloric intake of 91 per kilogram.

Baby 11565 , weight $2,680 \mathrm{gm}$., began to gain on the third day after a loss of $150 \mathrm{gm}$.; got $100 \mathrm{gm}$. on the third day and began to gain on that day. It gained $180 \mathrm{gm}$. in the succeeding six days; average daily caloric intake, 53 calories per kilogram. Average daily gain, $26 \mathrm{gm}$.

Another case, Baby 10570, gained $290 \mathrm{gm}$. in five days on an average caloric intake of 43 calories per kilogram of body weight. Average daily gain, $58 \mathrm{gm}$.

This infant lost $290 \mathrm{gm}$. in the first two days, and regained the birth weight on the seventh day. None of these infants had any water. These are only a few of many similar cases.

It is apparent, therefore, that infants, at least during the first ten days, in order to gain reasonably in weight do not require anywhere near 100 calories per kilogram of body weight, that the energy quotient varies in the individual cases from 43 to 75 , and that when new-born infants during the first ten days receive 100 calories per kilogram they are usually overfed. I say usually, because there are patients who will tolerate enormous quantities of food, gain steadily and rapidly for considerable periods of time without any evidence of digestive or systemic disturbance.

Regarding the caloric needs of premature infants, it is generally agreed that it is higher than for normal, full-term infants, generally conceded to be from 110 to 120 calories per kilogram.

Baby M., premature, 7 months; birth weight, $1,920 \mathrm{gm}$.; was given $85 \mathrm{gm}$. milk on the second day and increasing amounts up to $260 \mathrm{gm}$. on the sixth day, but continued to lose weight daily and lost $50 \mathrm{gm}$. on that day, on an average caloric intake of 88 calories per kilogram. The following day the amount was pushed up to $300 \mathrm{gm}$., equivalent to 100 calories per kilogram, and the baby gained $10 \mathrm{gm}$. On that day. It was kept on $300 \mathrm{gm}$. for the next twenty days and gained an average of $10 \mathrm{gm}$. per day, being discharged on the twenty-eighth day, with a weight of $2,140 \mathrm{gm}$.

Initial Loss in Weight.-According to Camerer, Schlossman and many others (Camerer's figures are generally copied) the initial loss in new-born infants occurs during the first two or three days and amounts to an average of $200 \mathrm{gm}$. "After the third day there is a 
steady gain of about $30 \mathrm{gm}$. per day, and by the eighth or tenth day the baby has regained its birth weight" (Camerer).

In our series of cases the average initial loss was $240 \mathrm{gm}$. and the average time the loss continued was three days.

There have been many theories advanced as to the cause of the initial loss. These theories are so familiar that they need not be enumerated. The chief cause has generally been assumed to be the lack of food and fluid during the first days.

Shick ${ }^{4}$ by means of complementary feeding with mother's milk was able in nine cases to prevent the initial loss in weight. The complementary feeding was begun from three to six hours after birth and repeated every two or three hours. An amount equal to from 8 to 15 per cent. of the body weight was given irrespective of the amount received from the nursings. None of the infants suffered any inconvenience, and two actually gained in weight.

In looking over our series of charts it was noticed that the initial loss varied greatly in the individual cases and in some the loss was out of all proportion to the lack of food and fluid. For example, No. 12452 , weight $3,740 \mathrm{gm}$.; got $37 \mathrm{gm}$. milk on the second day and had lost $255 \mathrm{gm}$. by the third day; while No. 12505, weight $3,930 \mathrm{gm}$., received $60 \mathrm{gm}$. milk on the second day, had no apparent loss in weight and began to gain on the third day.

The infants who are apparently normal, receive an average amount of milk, and show an unusual drop in weight at the second weighing, are frequently those who have a large amount of meconium and perhaps urine and do not pass it until after they are weighed. There is also a marked difference in the amount of vernix caseosa in different cases; so that the removal of this, coupled with the discharge of meconium and urine after weighing, would account for a considerable drop at the second weighing.

Baby 12505, who showed practically no initial loss of weight on the second day, passed a large amount of meconium at birth and had little vernix caseosa.

The continued loss in weight after the second or third day in normal infants seemed to depend on whether there was a lack of an average secretion of milk.

Concerning the effects of water in diminishing the initial loss in weight, every other baby in the series was given water up to 2 ounces after each nursing. This did not seem to affect the initial loss when an average amount of milk was secreted, the loss being as great in those who received water as in those who received none. In cases in which there was practically no milk secreted, the patients who received

4. Shick: Ztschr. f. Kinderh., December, 1915. 
water lost less than those who received no water. After the third day, if the milk was insufficient, water seemed to have no effect in restoring the initial loss or in preventing further loss.

The gain in weight seemed to depend on an average amount of food, varying from 43 to 74 calories per kilogram of body weight.

The initial loss in large infants, contrary to what has been generally accepted, was not relatively greater than in small ones. This agrees with Bergman's ${ }^{5}$ findings.

Only about one fourth of the infants regained their birth weight before leaving the hospital on the tenth day. This agrees with Bergman's findings in 1,000 cases; only about 21 per cent. had regained the birth weight by the fourteenth day, and more than half did not regain it up to the twenty-first day.

The average daily gain in weight after the third day was about $20 \mathrm{gm}$. making a total average gain of $140 \mathrm{gm}$. while in the hospital, so that three fourths of the infants left the hospital on the tenth day with an average weight of $100 \mathrm{gm}$. less than the birth weight.

Stools.-There is a great diversity of opinion among authorities as to the normal number of stools of infants during the first weeks. The number, according to different observers, varies from two to six. In our cases the stools averaged less than two per day.

In several infants who were being overfed for metabolism work, the stools became frequent and watery whenever the quantity of milk in twenty-four hours began to approximate 100 calories per kilogram. One of these cases was particularly instructive:

Baby Anderson, birth weight, 3,580 gm., was born at $7 \mathrm{p}$. m. and got $30 \mathrm{gm}$. breast milk that evening. Weights, amount of milk and loss for the first twelve days were as follows:

\begin{tabular}{|c|c|c|c|}
\hline Day & $\begin{array}{c}\text { Weight, Gm. } \\
3,530 \\
3,470 \\
3,600 \\
3,670 \\
3,650 \\
3,750 \\
3,750 \\
3,740 \\
3,730 \\
3,710 \\
3,710\end{array}$ & $\begin{array}{l}\text { Milk, Gm. } \\
\text { got } 255 \\
\text { got } 290 \\
\text { got } 415 \\
\text { got } 480 \\
\text { got } 540 \\
\text { got } 750 \\
\text { got } 750 \\
\text { got } 670 \\
\text { got } 775 \\
\text { got } 535 \\
\text { got } 550\end{array}$ & $\begin{array}{l}\text { Gain or Loss in } \mathrm{Gm} . \\
\text { gain } 50 \\
\text { gain } 60 \\
\text { gain } 130 \\
\text { gain } 70 \\
\text { loss } 20 \\
\text { gain } 100 \\
\text { no gain or loss } \\
\text { loss } 10 \\
\text { loss } 10 \\
\text { loss } 20 \\
\text { no loss or gain-discharged }\end{array}$ \\
\hline
\end{tabular}

This illustrates what happens usually in overfed cases; the infants gain for a while, then, after their tolerance is exceeded, they remain stationary for a time and gradually begin to lose in weight.

These overfed infants were the only ones in which the stools were frequent and exceeded an average of two in the twenty-four hours.

5. Bergman: Ztschr. f. Kinderh., March, 1916. 